\title{
LA FERIA DE BEJAR EN EL SIGLO XV
}

\author{
Gloria Lora Serrano \\ Universidad de Sevilla
}

\section{INTRODUCCION}

Son numerosos los trabajos en los que se ha puesto de manifiesto la importancia que tuvieron ferias y mercados en la economía de las ciudades y villas castellanas del Medievo, así como el papel fundamental de ambas celebraciones en el resurgimiento de las ciudades y del comercio en la Edad Media. Sin embargo, la investigación sobre estos temas es escasa. Al decir del profesor Valdeavellano el estudio del mercado medieval está por hacer entre nosotros (1). Pero, a pesar del interés que nos suscitan las ferias y los mercados castellanos de la Baja Edad Media, el objetivo de este trabajo es otro: no se trata de hacer un análisis de una feria de una villa de Castilla a fines de la Edad Media puesto que estudios sobre ferias, aunque pocos, existen, sino que nos vamos a centrar en analizar las ordenanzas por las que esa feria se regia. Pensamos que bajo el ordenamiento frío y seco por el que se debía organizar esta feria y los mercaderes que a ella acudian, latía un mundo mucho más vivo y brillante, como era la vida urbana y comercial de la Béjar del siglo $\mathrm{XV}$.

Hemos considerado oportuno publicar el texto íntegro de las ordenanzas, porque, si bien, con frecuencia, nos aparecen los documentos fundacionales de las ferias, no son tan corrientes los textos que nos hablan acerca de su funcionamiento interno, razón por lo que éste nos ha parecido interesante. Así mismo, nos parece conveniente dar unas brevísimas notas acerca del lugar donde se dictaron estas ordenanzas y de su autor (2).

El nacimiento de Béjar, se debe, como el de tantos otros lugares de la frontera, a la necesidad de los monarcas de defender las zonas más vulnerables del reino. La villa, parece que se fundó entre octubre o principios de noviembre del año 1208, meses en los que Alfonso Vill estaba en 
Talavera y Escalona ocupado en tareas repobladoras (3). El primer documento conocido sobre la fundación de Béjar es el que Alfonso Vill dio al concejo de Avila donde se señalaban los términos por donde iba la línea divisoria entre Avila y Béjar. Su fecha es la del 5 de enero de 1209 (4).

Con seguridad, Béjar tuvo un fuero desde el momento de su repoblación; aunque hasta 1260 , el fuero de Béjar "no era sino un conjunto de usos, costumbres y privilegios concedidos por un rey, confirmados o fijados bajo otro, nacidas a partir de un amplio privilegio de repoblación concedido por Alfonso VIII, que no tuvo necesariamente que quedar fijado por escrito" (5). Sin embargo, el fuero que nosotros conocemos es otro: está en un códice de fines del siglo XIII o principios del XIV y se custodia en el Archivo Municipal de Béjar (6).

Los primeros documentos de Béjar que han llegado hasta nosotros nos hablan de una villa con un fuerte carácter ganadero y que prosperó con rapidez (7). Su primitivo asentamiento fue en un valle situado al Sur de su actual emplazamiento, pero por motivos de higiene y seguridad, Alfonso XI lo ordenó trasladarse a una loma vecina (8).

Las noticias que poseemos acerca de los primeros señores que tuvieron un dominio más o menos efectivo sobre Béjar son confusas. Sabemos que la Sentencia arbitral de Torrellas dio la villa a Don Alfonso de la Cerda que la consiguió en 1304 junto a Alba de Tormes, Valdecorneja, Gibraleón y otros pueblos, a cambio de renunciar a sus derechos al trono de CastiIla (9). Despojado más tarde de ella por no haber cumplido lo establecido en la Sentencia, Béjar permaneció unida a la Corona (10). Durante los turbulentos años que duró la minoría de Alfonso XI, la villa sufrió graves daños por parte de los partidarios del infante Don Juan. Recuperado el poder real, Alfonso XI concedió a los vecinos de Béjar una serie de privilegios y exenciones de tributos (11). Nuevamente es apartada la villa de la jurisdicción real al serle entregada a uno de los hijos de Alfonso XI y Leonor de Guzmán: Sancho el Mudo (12), quien en 1333 aparece en la documentación confirmándole al concejo de Béjar los fueros, privilegios y costumbres que siempre había tenido la villa (13). De don Sancho, pasó Béjar a manos de sus hermanos (14).

Posteriormente, Enrique II concedió Béjar a Diego López Pacheco, emigrado portugués, infatigable agente del partido trastamarista que asesinó a doña Inés de Castro (15). La fecha exacta de la donación la desconocemos, pero en 1364 quizás detentase el señorío, pues desde ese año hay un cierto número de documentos en los que los escribanos públicos de Béjar aparecen a merced de «su señor Don Diego López» (16) y evidentemente no se puede tratar de Diego López de Estúñiga, cabeza de uno de los linajes más poderosos y representativos de la nueva nobleza castellana que se instala en el poder tras la implantación de la dinastía Trastamara, y señor de Béjar desde junio de 1396 (17). 
Sobre la figura de Diego López y su linaje se ha escrito con frecuencia (18). No es este el lugar de profundizar sobre el tema aunque sí de señalar la enorme importancia de este caballero en la Castilla de la época. Hijo de Iñigo Ortiz de Estúñiga, cortesano de Pedro I, y de Juana de Orozco, Diego López de Estúñiga, iniciará su ascensión en el reino como camarero del principe Juan, el futuro Juan I, quien siendo príncipe le concedió las primeras mercedes: en octubre de 1377 el señorio de Bañares y en 1380 Juan I le dio un juro de $2.400 \mathrm{mrs}$. situados sobre unas rentas de sal de diversos lugares castellanos (19). Tras importantes compras entre las que cabe destacar las de la villa de Capilla con su puente para ganados trashumantes que fue una fuente grande de beneficios, que hace en 1382 al Justicia Mayor Juan Núñez de Villasán (20), y la villa de Burguillos en 1393 (21), además de importantes bienes y heredades en tierras andaluzas (22), Diego López de Estúñiga va conformando su dominio señorial con nuevas mercedes por parte de Juan I -quien en 1382 le da los lugares de Valdarrago y Bodón cercanos a Ciudad Rodrigo (23), y las tercias del arcipreztasgo de Peñafiel (24) - así como del infante don Fernando, quien en 1395 le hace merced de Besquera, en la ribera del Duero (25).

Don Diego López completará su extenso patrimonio con una serie de inteligentes trueques entre los que destacó la obtención de Curiel a cambio de ceder al dominio del rey, Villalba de Losa (26), y sobre todo, para nosotros, resulta interesante el cambio que hizo Diego López de su villa de Frias por la de Béjar, que Enrique III habia heredado de su madre la reina doña Beatriz (27). El rey castellano apetecía Frias por la extraordinaria fortaleza y buena situación estratégica que poseía y Diego López de Estúñiga con toda seguridad, deseaba Béjar por la inmejorable situación geográfica, económicamente hablando, pues por la villa pasaba una de las cañadas de la mesta con lo cual podía obtener saneadas rentas. Así, como hemos indicado antes, desde junio de 1396, los Estúñigas dominarán Béjar cuya obtención junto a sus numerosas aldeas marca uno de los hitos más importantes dentro de la meteórica carrera de Diego López de Estúñiga (28).

Al importante dominio territorial que logró reunir, habría que añadir la jurisdicción con mero y mixto imperio sobre la mayor parte de los territorios que poseía. Estos se extendian por amplias zonas de Extremadura, Andalucia y por las provincias de Salamanca, Valladolid, Burgos y Logroño. Además de este importante patrimonio, Diego López de Estúñiga detentaba gran poder e influencia en la Corte, pues no en vano desde 1395 era el Justicia Mayor (29) y, lógicamente, hubo de aprovechar las buenas relaciones con Enrique III y Juan II para acrecentar su patrimonio y enaltecer su linaje.

En 1397 dicta testamento donde funda un mayorazgo a favor de su hijo Pedro, mayorazgo que fue reformado y ampliado sucesivamente en testamentos y codicilos posteriores hasta 1417, año en que muere (30). En 
definitiva, Diego López de Estúñiga dejará a su muerte una ingente labor: de ella, el profesor Ladero dice: «su obra facilita el mejor modelo que pueda imaginarse sobre la forma de constitución de un poder señorial en la Castilla de los Trastamara: por los mismos caminos cortesanos, aspiraciones y logros transitaron muchos aristócratas, casi nunca con tan buena y duradera fortuna" (31).

Su hijo y sucesor, Pedro I de Estúñiga, continuará la obra de su padre, acrecentando su hacienda, pues a los cuantiosos bienes heredados de Diego López, le añadió los aportados por su mujer doña Isabel de Guzmán, en Andalucia, y otros que él consiguió personalmente (32). De una manera muy sucinta podemos decir que su patrimonio lo componian las villas de Béjar, Burguillos, Capilla, Curiel, Pesquera, Traspinedo y Villacovancio; los lugares de Urbel con su castillo, Ciadoncha, La Algaba, Gatos, Chillas y Garruchena. Rentas y propiedades diversas en Peñafiel, Burgos, Valladolid, Santa Cruz de Inarros, Coscorrita, Revilla del Campo y La Mata, además de gran número de casas y bienes en Sevilla y su provincia, y una importante cantidad de maravedies situados sobre diversas rentas y juros (32).

Con este importante patrimonio territorial y con una acertada actuación política, Pedro de Estúñiga encumbró aún más a su linaje. Como Alcalde Mayor de Sevilla participó activamente en el Concejo de la ciudad, y a través de éste en la vida de la misma (33). A la muerte de su padre fue nombrado Justicia Mayor del reino, obteniendo por tanto una privilegiada situación en la Corte (34). En 1429 Juan II le hizo merced de la villa de Ledesma con señorío sobre esta plaza y con título de conde (35). A partir de 1430 y en los años sucesivos, Pedro de Estúñiga nos aparece actuando valerosamente en la frontera granadina (36), de donde fue nombrado Capitán Mayor de la Frontera (37).

En 1440 recibe una nueva merced de Juan II: en esta ocasión se trató de la importante plaza de Trujillo (38), pero ante la tenaz resistencia presentada por la villa, Juan II le prometió Plasencia (39), villa que obtuvo en $1442(40)$.

Son los años de mayor actividad política de Pedro de Estúñiga, que ahora detenta gran poder en el reino, tomando parte en los principales sucesos que acaecen en el momento, político sumamente astuto, fue partidario del condestable Don Alvaro de Luna cuando esto le valió para defender sus intereses personales. No obstante, junto a su hijo Alvaro, participó directamente en la caída y posterior prisión del valido en 1452 (41). Son también en estos años cuando Pedro de Estúñiga se encuentra con frecuencia en su villa de Béjar, donde se retiró cuando por la enemistad mantenida con el Condestable, el señor de Béjar fue alejado de la Corte (42).

A su muerte ocurrida en Valladolid en 1453, heredó el mayorazgo su hijo Alvaro, quien hasta 1488 disfrutó y gobernó el señorío. Como su antecesor detentó los cargos de Justicia Mayor del reino (43) y de Alcalde 
Mayor de Sevilla (44). También, igual que Pedro I, desde época bastante temprana participó directamente en la política de Castilla, formando parte de las ligas nobiliarias que se organizaron en el reino, aunque siempre atento a colaborar con el bando que más provechoso le fuera a su linaje (45). Como partidario del marqués de Villena estuvo junto a la nobleza que depuso a Enrique IV en Avila (46). Siendo adicto al príncipe Don Alfonso obtuvo de éste la merced de Trujillo (47), que le sería confirmada por Enrique IV tras la muerte de su hermano, pero al no poderle entregar la villa por la oposición de los trujillanos a entrar en señorío (48), Alvaro de Estúñiga recibió del Rey la promesa de la obtención de la villa de Arévalo (49), que la consiguió con título ducal en 1469 (50).

A la muerte de Enrique IV y durante la guerra de sucesión que siguió a aquella, Alvaro I de Estúñiga dio muestras de una gran astucia política: a pesar de ser junto al marqués de Villena uno de los más firmes baluartes de la causa de la princesa doña Juana, permitió que sus hijos Pedro y Alvaro fuesen fieles al partido de Isabel y Fernando. Como vasallo rebelde, la reina Isabel lo va a privar de todos sus bienes que pasaron por ser mayorazgo a su hijo mayor Pedro (51) quien además en esta ocasión se vio premiado con la obtención del cargo del Alguacil Mayor (52).

Tras la victoria de los Reyes Católicos frente a los nobles insurrectos, Don Alvaro de Estúñiga se dispuso a negociar. El anciano duque de Plasencia contó en estos momentos con la inapreciable ayuda de sus hijos Pedro y Alvaro, que militaron en el bando de los vencedores (53), por lo que sin grandes dificultades pactó con aquellos. El acuerdo entre los Estúñigas y los Reyes Católicos se firmó en las Cortes de Madrigal de 1476: mediante el mismo Don Alvaro y todo su linaje volvian a Ja obediencia de Isabel y Fernando. Estos, le devolvían a don Alvaro todos los bienes y oficios que le habian sido confiscados y además, otorgaban a Juan de Estúñiga, el maestrazgo de Alcántara (54). Sin embargo, Alvaro de Estúñiga perdió la villa de Arévalo que fue a parar a la Corona (55), pero obtuvo los títulos de duque de Plasencia y conde de Bañares (56).

Las discordias suscitadas por la herencia de Alvaro I de Estúñiga permitieron a los Reyes Católicos recuperar Plasencia, aunque su nieto y sucesor Alvaro II de Estúñiga pasó a titularse por entonces duque de Béjar. La villa, como cabeza de Estado prosperó enormemente y tuvo una amplia jurisdicción sobre la comarca (58). Gozó de la predilección de los duques de Béjar quienes la eligieron para pasar largas temporadas en ella. El hermoso palacio renacentista - del que aún se puede apreciar una parte - comenzado a construir en estos años sobre otro allí existente, es prueba fehaciente de aquello.

\section{EVOLUCION HISTORICA DE LA FERIA DE BEJAR}

Los primeros datos que poseemos acerca de la feria de Béjar son los que nos proporciona el fuero de esta villa, otorgado como dijimos ante- 
riormente a fines del siglo XIII o comienzos del XIV (58). De esas noticias, por lo demás bastante parcas, se desprende que casi desde la época fundacional de Béjar, la villa poseía una feria anual celebrada durante los ocho días que seguian a dicha fiesta. Igual que ocurría en otras ferias españolas, se establecian garantías de seguridad para las personas que acudiesen a la festividad (59).

Las ordenanzas de la feria sobre las que versa nuestro estudio se refieren sin embargo a otra: la que Juan II concede a la villa el 10 de abril de 1407 (60). Hay noticias de que antes de ese año se celebraba ya dicha feria, en concreto parece que desde el año 1398 (61).

El albalá que ha llegado hasta nosotros, gracias al cual sabemos la concesión de Juan II a Béjar de su feria, es bastante simple: en unas cuantas líneas nos dice que Juan II por hacer merced a Diego López de Estúñiga, y al concejo de Béjar, concedia a la villa facultad para celebrar una feria anual que se desarrollaría entre los días 1 y 15 de agosto (62). En realidad, lo que Juan II hizo fue darle a esta feria que ya se venía celebrando, un carácter más legal. Es interesante señalar que, al parecer, esta concesión se hizo por ruego del Justicia Mayor (63), cosa que no nos puede extrañar ya que no podemos olvidar que la concesión por parte de un monarca de una feria a cualquier población era considerada como una gran merced, no sólo por la animación y enriquecimiento que obtenía la ciudad donde se celebraba a causa de las gentes que recibía, sino también porque fue frecuente por parte de los reyes la concesión de la franquicia de la misma (64), como hizo Juan II en el caso que nos ocupa (65). En efecto, el atraso que la política tributaria de las ferias suponia para los mercaderes que acudían a las mismas debido a los numerosos impuestos con que se gravaban las transacciones comerciales efectuadas en ellas, entorpecian las actividades financieras, rodeándolas de cargas fiscales, lo que motivó la liberación de éstas por parte de los reyes que por medio de franquicias reales facilitaban enormemente el comercio en estas celebraciones (66). Asi pues, Juan II estableció que la feria de Béjar gozase de las mismas libertades y franquezas que tenían las otras ferias castellanas y por último mandaba pregonar su albalá en otras ferias y mercados para que se tuviese conocimiento de ello (67).

De la historia de la feria de Béjar conocemos relativamente poco. Un breve relato sobre la misma nos dice que el concurso de gentes que acudian y de géneros que se ofrecían era enorme y que lógicamente, producía bastante dinero a los señores de la villa (68).

En cuanto a su situación topográfica podemos decir que, como otras ferias y mercados de Castilla, las tiendas y mercaderes que allí acudían se situaban en las afueras de la villa, en la llamada Corredera, y llegaban hasta el interior del pueblo (69). Las caballerias se colocaban en un campo anejo a la Corredera que era bastante amplio; Ios ganados vacuno, lanar y cabrío en la justa y mesta, los cerdos en el territorio de la solana 
alta y baja y los géneros de curtidos, cordobanes, ante y en general de pieles, en el campo del rollo (70).

A juzgar por las rentas que los señores de Béjar obtenían de la celebración de la feria (71) y el interés por su buen funcionamiento - prueba de aquello son estas ordenanzas - la historia de ésta tuvo que ser floreciente. Hay una carta de los Reyes Católicos otorgada en Córdoba en 1485 en la que éstos hacian saber que las personas que acudian a la feria de Béjar no incurrian en ninguna pena (72). En efecto, años antes, doña Isabel y don Fernando -ante las quejas presentadas por los procuradores en Cortes en el sentido de que en muchas villas que tenian mercados y ferias francos sólo se vendia productos en días de mercado, lo que iba en detrimento de las personas con escaso poder adquisitivo y también de las rentas reales (73) - habian dado una carta para que ninguna persona fuese a comprar o vender a ninguna feria franca que se celebrase en el reino (74). A petición del entonces señor de la villa, Alvaro I de Estúñiga, que temia que se dejase de asistir a la feria de Béjar, la reina Isabel dio un albalá diciendo que las prohibiciones dadas con anterioridad no afectaban a la feria de Béjar, puesto que la villa la tenía otorgada desde antiguo y el ordenamiento dado por la reina no afectaba a las antiguas, y para evitar más confusiones doña Isabel mandó pregonar este ordenamiento (75), lo que sabemos que se hizo días después en Medina del Campo (76). Años más tarde, la reina Católica dio otra carta confirmando lo anterior y añadiendo que se podía acudir también libremente a la feria de Gibraleón, otra villa de los Estúñigas, y de reconocida antigüedad, y que como la de Béjar no era franca, ya que pagaba la alcábala de los productos que se comercializaban (77).

\section{ORDENANZAS DE LA FERIA}

Las ordenanzas que conocemos fueron hechas por Pedro I de Estúñiga y publicadas el 24 de agosto de 1452 . Estas fueron confirmadas por su hijo Alvarol en Béjar el 23 de agosto de 1456 y el texto de esta confirmación, más el traslado de las ordenanzas de Pedrol, son los documentos que han llegado hasta nosotros.

Las ordenanzas se dieron con un evidente interés fiscal porque, según se declaraba, fueron elaboradas para evitar excesos y fraudes entre vendedores y arrendadores de impuestos de la feria a causa de la alcabala que había que pagar por los géneros que se compraban y vendían en la misma (78). Es interesante destacar que estas ordenanzas las confirmó Alvaro I de Estúñiga a petición de los mercaderes que acudian a la feria, lo que nos puede indicar cierto descontento por parte de estos comerciantes con los arrendadores de las alcabalas de Béjar (79).

Las ordenanzas de la feria de Béjar que estudiamos, se refieren tan sólo a ciertos aspectos de esta celebración. En primer lugar, hay que señalar los productos que alli se comercializaban. Por la lectura del texto 
sabemos que el comercio de paños tuvo una excepcional importancia en Béjar. Los había de las más variadas procedencias: entre los extranjeros vemos citados paños flamencos, brabanzones o ingleses. Pero también se comercializaban paños castellanos como las blanquetas, paños pardiIlos, brunetas y bureles. En cuanto a las calidades de los tejidos, los había desde las granas, utilizadas fundamentalmente para la confección de ricos vestidos de fiesta, o los exquisitos paños de oro y de seda, a las humildes blanquetas, usadas asiduamente por las gentes del común. Fustanes, cendales, paños negros de caldera, etc., son también citados en las ordenanzas como tejidos vendidos corrientemente.

El documento nos habla, asimismo, de la venta de otros productos de lujo en esta feria, tales como plata, oro, joyas, piedras preciosas, perlas, aljofar, tapices, alfombras y tapetes, algunos de los cuales procedían de Francia. Sólo estos artículos son citados en las ordenanzas, pero evidentemente no eran los únicos comercializados en la feria. Animales como vacas, ovejas, cabras, cerdos y sus derivados, como por ejemplo pieles, nos consta, documentalmente, que se encontraban expuestos para su comercio en la feria (80). Aunque no tenemos referencia documental alguna, no es difícil imaginar que productos de primera necesidad, como vino, trigo y otros cereales, o bien objetos de loza, barro y metal, es decir, aquellos artículos precisos para la vida diaria, eran vendidos igualmente.

Las ordenanzas contemplan y legislan otros aspectos de la feria. Uno de éstos es la prohibición de jugar a los dados, probablemente para evitar riñas y cuestiones que alteraran de alguna manera la paz, algo inherente a este festejo (81). El fuero de Béjar se refiere a ésta y en el punto 32 nos dice: «Prouecho e ondra uos otorgo ferias ocho dias antes de cincuaesma e ocho dias despues. Qui viniere a estas ferias, cristiano, o moro o judio, uenga seguramientre e qui mal le fiziere o lo trabaiare, al rey mil morabedis peche en coto e el danno duplado al querelloso. Si non ouier onde lo peche, espiendanle el cuerpo. Qui lo matar, soterrar al uiuo so el muerto. Si firiere taiarle la mano. Si en las ferias matar alguno algun omne, meter el uiuo so el muerto. Si firiere tajarle la mano. Qui arrebatare alguna cosa, peche al rey mil moravedis en coto e el danno duplado al querelloso. Si non ouier onde lo peche, despennarlo. Qui furtare, despennarlo otros$\sin (82)$.

Ignoramos qué castigo recibirían a mediados del siglo XV aquellos que incurriesen en esos delitos. Lo que sí sabemos es que los que fuesen hallados jugando a los dados en dias de feria, perderian todos los mrs., doblas, florines $u$ otras monedas que tuviesen sobre la mesa, además de pagar cada jugador $60 \mathrm{mrs}$. de multa. Si volvían a jugar la pena aumentaba a $120 \mathrm{mrs}$. y diez días en la cárcel. Los recincidentes en el juego hallados por tercera vez tendrian que abonar $600 \mathrm{mrs}$. o recibir 50 azotes. El autor de las ordenanzas estableció que las multas se cobrasen y repartiesen de la siguiente manera: un tercio para la Cámara señorial, otro para el acusador y el tercio restante para la justicia que lo tomare. 
La dificultad para encontrar alojamiento en Béjar en estas fechas en las que la villa veía aumentada considerablemente su población, hizo que el conde don Alvaro añadiese a las ordenanzas dadas por su padre, un capítulo en el que también, con el fin de preservar la paz de la feria, se estableciera lo que se debia satisfacer por el alquiler de una casa. En efecto, al parecer fueron frecuentes las disputas entre los mercaderes que acudían a la feria y los propietarios de las casas por la renta que se pretendía cobrar. Se estableció, pues, que se nombrasen tres personas - una por parte del conde, otra por parte de los mercaderes y la tercera en nombre de la villa, que era una de los alcaldes y que, visto el aposentamiento y el servicio que se ofrecía a los huéspedes, tasaran el alquiler que se debía pagar (83).

Por último, se dan en estas ordenanzas una serie de normas sobre los corredores que acudian a la feria. En primer lugar se atiende a su número, estableciéndose éste en doce que serían elegidos por dos personas-una representante del conde y otra por parte de los mercaderes-. Antes de actuar como tales, corredores elegidos y mercaderes debian jurar lo establecido acerca de su trabajo por las ordenanzas. Según éstas, los doce corredores estarían presentes solamente en las transacciones comerciales de paños y telas. Las dos personas encargadas de elegirlos tendrían también la tarea de examinar las disputas entre mercaderes y corredores. El ordenamiento establece minuciosamente lo que los corredores deberían cobrar por su trabajo de correduria, así como las multas que estarían obligados a pagar en caso de que percibiesen más de lo estipulado. El producto de estas multas sería recaudado y dividido de la misma manera que el de las ocasionadas por jugar a los dados.

De la lectura de estos capítulos de las ordenanzas podemos deducir que debieron ser bastante frecuentes los abusos por parte de los comerciantes que acudían a la feria, hecho al parecer muy común en otras ferias y mercados de Castilla. Por ello, fueros y ordenanzas, tanto municipales como señoriales, intentaban atajarlos. Ya, anteriormente, hemos hecho notar cómo estas ordenanzas fueron confirmadas por Alvaro I de Estúñiga a petición de los mercaderes descontentos por ciertos atropellos cometidos, al parecer, por los arrendadores de las alcabalas (84). Evidentemente, con el mismo fin de evitar abusos y aclarar situaciones, Pedro I publicó estas normas sobre los corredores, estableciendo también que cualquier mercader que engañase al comprador vendiendo un paño de baja calidad a precio superior al real, perdiese el paño y el corredor presente estuviese veinte dias en la cárcel.

¿Fue este hecho algo usual en la feria de la época? Es algo arriesgado de afirmar, pero es una idea que nos sugiere el texto estudiado. Sea como fuere, sí que creemos poder asegurar el extraordinario interés por parte del señor de la villa en el funcionamiento de su feria sin ningún tipo de problemas ni trabas, tanto de indole institucional como económica y social, por ello se preocupa de garantizar la legalidad de la feria, buscán- 
dose las oportunas mercedes y dicta normas acerca de las relaciones económico-sociales que deben ser guardadas. Todo, en definitiva, nos pone de manifiesto un hecho importante en la Castilla Bajomedieval: el creciente interés de la nobleza en materias económicas, dominando los medios de producción, controlando los intercambios comerciales y obteniendo, en definitiva, unas saneadas rentas, que, en cierto modo, le ayudasen en la consecución de sus aspiraciones políticas.

\section{TEXTO DE LAS ORDENANZAS}

Traslado de las ordenanças quel conde mi señor dio e otorgó a la feria de Béjar este año de UCCCLVII años

Yo don Aluaro de Stunniga, Conde de Plasençia, Justiçia mayor de Castilla e Señor de Gibraleón, por quanto el conde mi señor que Dios aya, ovo mandado faser çiertas ordenanças tocantes a los mercaderes que suelen venyr a la feria desta mi villa de Béjar, por los quales a mi es pedido las mande confirmar, su thenor de las quales son estas que se syguen:

De los paños de Ypres mayores e cestres e Brujas mayores e Londres, e otros pannos de las suertas destos, poco más o menos, que se vendieren por vara, que pague los dichos mercadores de cada millar de la dicha ropa treynta e çinco mrs. al millar.

Yten de Belates e granas e ryanes del sello, e liuas mayores, e florentines e otros pannos destas suertes e sysas semejantes poco más o menos que se vendiere por vara que paguen treynta mrs. de cada millar.

E de fardeles e pannos enteros e pieças de todos los sobre dichos en los capítulos ençima escriptos, e asi mismo de los Yprés menores e contrays menores e ruanes menores, e otros semejantes que se vendieren por fardel por pieça entera, que paguen a dose mrs. el millar segund que se costumbra pagar en la feria de Medina del Campo.

Yten, Yprés menores e ruanes menores e contrays menores e Sanjuanes menores e Brujas menores e bernis de Flandes e otros de semejante guisa, que paguen quarenta mrs. de cada millar de lo que se vendiere por vara.

Yten, blanquetas e pannos que se fasen en Castilla que se vendiere la vara dellos a setenta o ochenta o fasta cient $\mathrm{mrs}$. la vara o dende ayuso que paguen de cada pieça de panno a treynta e ocho mrs. E pannos negros de caldera e butieles prietos e pardos e blancos que paguen a veynte e ocho mrs. segund la costumbre de los annos pasados. Pero sy los dichos pannos pardillos o brunetas o otros pannos de la tierra se vendieren más de a ciento mrs. la vara que paguen quarenta mrs. de cada millar.

Yten, de las forsas que se paguen de cada pieça veynte mrs.

Yten, de los fustanes e çendales, que se paguen por pieça a çinco mrs. de cada una pieça. 
Yten, de la plata e oro que se vendiere e pannos de oro o seda que se paguen çinco mrs. por el millar.

Yten, que ninguna persona cristianos, ni judio ni moro de qualquier ley o estado o condiçión que sea non juegue dados en la feria so pena que todos los que fueren fallados jugando pierdan todos los mrs. e doblas e florines e otra moneda que touieren al tablero, e demás que por la primera ves que fuere fallado que jugaren que paguen de cada uno sesenta mrs., e por la segunda que paguen la pena doblada e esté dies dias en la cadena, e por la terçera vesada sy fuere omes de mañas, que paguen seysçientos mrs. e sy fueren omes de poca guisa, que le den cinquenta açotes por la villa e que las dichas penas sean la tercia parte para el acusador, e la otra terçia parte para la justiçia que lo escundare.

Yten, que los corredores que ouieren de ser en la feria de los pannos e fustanes, que sean número de dose e non más, e estos corredores que sean unos omes escogidos por dos personas, uno por parte mia e otro por la parte de los mercadores. E que estos dos que lo asy ouiere de escoger, tengan cargo de esaminar los debates que ouieren entre los mercadorese entre los corredores unos con otros.

Otrosy, los dichos corredores lieuen de corredoria de cada ciento de lo grueso, un mrs. e non más, e de cada vara de lo delgado otro mrs. de San Juan arriba, e de la pieça de lo grueso entero tres mrs. e de lo delgado de San Juan arriba çinco mrs. por pieça entera, e de los fustanes, un mrs. de cada pieça e de los pannos de seda e oro e plata e joyas e otras cosas seisçientos dos mrs. de cada millar. E qualquier corredor que más leuare de la dicha quantya, que pague por la primera vesada sesenta mrs., e por la segunda la dicha pena doblada, e esté dies dias en la cadena, e por la terçera, que le den cinquenta açotes por la villa. $E$ que las dichas penas se repartan en la manera de suso se contiene en las de los dados. E los mercadores non paguen de corredoria más de lo que de suso sey, so pena de cient mrs. por cada vesada e que los dichos deputados que han de escoger los dichos corredores, tomen juramento a los dichos mercadores e corredores que guarden todo lo susodicho.

Otrosi, que qualquier mercador que vendiere un panno por otro que lo pierda e sea deputado para fase limosna dello, e el corredor que estouiere en la tal venta, que esté veynte dias en la cadena.

Otrosy, que en la renta del lusillo non se faga nin en otros, saluo que arrendador e sus companneros la cogan juntamente segund que se suele coger.

Fueron pregonadas estas hordenanças por pregonero en la plaça pública desta villa de Béjar, en preçencia de mi Juan Rodriguez Gallego, escriuano del rey nuestro Señor, e en su nombre. Su notario público en la su corte e en todos los sus regnos e señorios, jueues, XXIIII dias del mes de agosto, año del Nasçimiento del nuestro Señor lhesu Xpo. de mil e quatroçientos e çinquenta e dos años. 
Testigos que fueron presentes al tiempo de pregonadas estas dichas ordenanças: el liçençiado Gil López de Madrid, oydor de la audiençia del rey, e Gonzalo Gómez, cambiador, vesino desta dicha villa, e Rodrigo de la Penna, e Pedro de Curiel, criados del contador del señor conde don Pedro de Stunniga, e Diego de Valladolid, criado del dicho liçençiado. Yo Gómez Ferrández, secretario de mi señor el conde la fise escreuir por su mandado. Gafias (en blanco) e alcalde de todas las ordenanças suso dichas, mando que se guarde e cumpla lo que se sygue.

Otrosy, de joyas de oro e piedras preçiosas e joyeles e perslas e aljofar, e pannos françeses de toda tapeçeria que paguen de cada millar çinco mrs.

Otrosy, tapeçes, alcaltifas e otras cosas semejantes que paguen dies mrs. el millar.

Otrosy, por quanto acesçe muchas veçes aver debates sobre los alquiler de las casas e los moradores dellas con los que vienen a la feria, mando que quando tales debates acaesçieren que sea deputado por los mercadores una persona, e por mi parte el mi recandador, e por parte de la villa uno de los alcaldes el aposentamiento e sobre que debatyere e el seruiçio de los moradores que fisieren a los huéspedes e todo ello bien visto tase e modere lo que se deua pagar de los tales alquileres sobre que ouiere debate. E aquello que por el les fuere tasado, se pague e no más ni menos.

Por ende, yo por la presente aprueuo e confirmo e ratyfico las dichas ordenanças e todo lo suso dicho, e mando que se guarde e cumpla en todo e por todo segund e en la manera que en ellas se contiene non amenguando ni exçediendo dellas cosa alguna. Fecha en la mi villa de Béjar, XIII dias de agosto año del Nasçimiento del nuestro saluador lhesu $X$ po. de mill e quatroçientos e çinquenta e seys años. El conde don Aluaro. Gafias. 


\section{NOTAS}

(1) GARCIA DE VALDEAVELLANO, Luis, El mercado en León y Castilla durante la Edad Media, Universidad de Sevilla, Sevilla, 1975, pág. 11.

(2) Tengo en curso de redacción mi tesis de doctorado sobre el linaje señorial de los Estúñigas, señores de Béjar.

(3) Sobre el nacimiento de la villa de Béjar pueden consultarse los siguientes estudios: GONZALEZ, Julio, El reino de Castilla en la época de Alfonso VIII, CSIC. Escuela de Estudios Medievales, Madrid, 1960. Del mismo autor, Reconquista y repoblación de Castilla, León, Extremadura y Andalucia (siglos XI al XIII), en La reconquista espeñola y la repoblación del pais, CSIC, Zaragoza, 1951. «Repoblación de la 'Extremadura leonesa' „, en Hispania, III (1943). También es fundamental para el estudio de la repoblación de Bejar la obra del profesor SANCHEZ ALBORNOZ, Despoblación y repoblación del valle del Duero, Buenos Aires, 1966. Noticias aisladas sobre la repoblación de Salamanca y su alfoz se encuentran eń la obra de Manuel GONZALEZ GARCIA, Salamanca: La repoblación y la ciudad en la Baja Edad Media, Centro de Estudios Salmantinos, Salamanca, 1973.

(4) GONZALEZ, Julio, El reino de Castilla en la época de Alfonso VIII, tomo II, pág. 462, doct. N. ${ }^{\circ} 834$.

(5) GUTIERREZ CUADRADO, J. M., El fuero de Béjar, Universidad de Salamanca, Salamanca, 1975.

(6) A(rchivo) M(unicipal) B(ejar), Caja de Hierro, Fuero.

(7) Como en otros lugares de la Península, la mayor parte de la documentación más antigua ha desaparecido. No obstante, se han conservado catélogos, asi como un cierto número de documentos, que se hallan en el Archivo Municipal de Bejar y en la sección de Clero del AHN, que nos permiten vislumbrar con relativa facilidad la historia primitiva de Bejar. Entre los inventarios más conocidos tenemos el de Antonio MARTIN LAZARO, «Colección diplomática municipal de la ciudad de Béjar", en Revista de Archivos, Bibliotecas y Museos, Madrid, 1921, y del mismo autor, la «Colección diplomática de la iglesia del Salvador de la ciudad de Béjar", en Revista de Ciencias Juridicas y Sociales de la Universidad de Madrid, XII (1921).

(8) QUADRADO, J. M., Salamanca, Avila y Segovia, Ediciones El Albir, Barcelona, 1979 págs. 258-259.

(9) FERNANDEZ MINGUEZ, Fernando IV de Castilla (1295-1312). La guerra civil y el predominio de la nobleza, Colegio Universitario de Alava, Vitoria, 1976, págs. 183-187; QUADRADO, op. cit., pág. 266.

(10) En mayo de 1312 Fernando IV estaba ocupado en la tarea de recuperar para la corona Béjar, ante el incumplimiento por parte de don Alfonso de la Cerda de lo establecido en Torrellas. GONZALEZ MINGUEZ, op. cit., pág. 323-324.

(11) Mediante privilegio de Alfonso XI fechado en 1322 en Valladolid, el Rey concedió a los bejaranos, que no pechasen excepto en los muros y torres de la villa y en los muros de los lugares del término, asl como eximió a dichos hombres de pagar la cabeza de los pechos y redujo de cada servicio que tenían que pagar al Rey $1.500 \mathrm{mrs}$. A.M.B., Colección Diplomática, 15.

(12) CERDA YRICO, F., Crónica de Alfonso el Onceno, Imprenta de don Antonio de Sancha, Madrid, 1787, pág. 200. La Crónica fecha este nacimiento en 1331. 
(13) A.M.B., Colección Diplomática, 19.

(14) QUADRADO, J. M., op. cit., pág. 267.

(15) SUAREZ FERNANDEZ, L., "La crisis de la Reconquista», en Historia de España dirigida por Ramón Menéndez Pidal, tomo XIV, pág. 71.

(16) El documento de 1364 ha desaparecido, pero en la sacristía de la iglesia parroquial del Salvador de Bejar se conserva una fotografía del mismo. Otros pergaminos en los que nos aparece este Diego López citado como señor de Bejar, en AHN, Clero, Carpeta 1876-1 y A(rchivo) P(arroquia) S(alvador) (B(éjar), Serie A, Documentos privados 14 y 15 . Estos documentos han desaparecido, pero MARTIN LAZARO, en su Colección Diplomática de la iglesia del Salvador de Béjar, los transcribe, págs. 115-118.

(17) AHN, OSUNA, Carpeta 4-3.

(18) Entre otros destaco los estudios de: VILLALOBOS, M. L., "Los Estúñigas. La penetración en Castilla de un linaje de la nobleza nuevam, en Cuadernos de Historia, VI, 1975, págs. 327-355; LADERO QUESADA, M. A., “Los señores de Gibraleón”, en Cuadernos de Historia, VII (1977), págs. 33-95; BENITO RUANO, E., «Lope de Estúñiga. Vida y Cancionero », en Revista de Filologia Española, LI, 1968, págs. 17-20; FERNANDEZ-DAZA ALVEAR, C., El señorio de Burguillos en la Baja Edad Media extremena, Institución Cultural Pedro de Valencia, Badajoz, 1981; GERBET, Marie Claude, “Majorat, strategie familiale et pouvoir royal en Castille", en Melanges offerts a Gautier Dalche. Annales de la Faculte des Lettres et Sciences Humaines de Nice, N. ${ }^{\circ} 1983$.

(19) AHN, OSUNA, Carpeta 171-3 y 4

(20) Ibidem, Carpeta 172-10 y Leg. $351-2^{-3}$.

(21) Compra de Verantevilla en 1391. Ibidem, Carpeta 59-2. Clavijo lo compró a Fernando de Rojas en 1394. Ibidern, Carpeta 51-17. Burguillos, en Leg. 339-14.

(22) Sobre las actividades andaluzas y compras de diversos bienes en esos lugares puede verse el articulo de LADERO QUESADA, Los señores de Gibraleón..., págs. 47 y sigs.

(23) AHN, OSUNA, Carpeta 10-11.

(24) Ibidem, Carpeta 53-13.

(25) Ibidem, Carpeta 11-3. Confirmación de la merced por Enrique III en Carpeta 53-19.

(26) Ibidem, Carpeta 53-11.

(27) La carta de trueque está fechada en Córdoba a 8 de junio de 1396. Ibidem, Carpeta 4-3.

(28) (por cuanto Frlas) "...segunt la fortalesa que ella tiene e segunt el lugar en que está es muy complidera para mi servicio e de los reyes que despues de mi vinieren, que toda via sea mia e suya dellos e nunca sea apartada de la Corona reals, en lbidem, Carpeta 4-3 bis. Documento inserto en 1420-febrero-16, Valladolid.

(29) Ibidem, caja especial 215-13-2.

(30) El testamento de 1397 en Leg. 213 (II)-19-27. Los de 11 de junio de 1401, 21 de junio de 1415 y 26 de febrero de 1417 en legs. 213 y 214 . Sobre el mayorazgo, ver trabajo de GERBET, op. cit., págs. 264 y sigs.

(31) LADERO QUESADA, M. A., "Rentas condales en Plasencia», en El siglo XV en Castilla. Fuentes de renta y politica fiscal, Ariel Historia, Barcelona, 1982, pág. 170.

(32) LADERO QUESADA, M. A., Los señores de Gibraleón..., págs. 58 y sigs.

(33) ORTIZ DE ZUÑIGA lo cita como Alcalde Mayor en 1406. Anales eclesiásticos y seculares de la muy noble y muy leal ciudad de Sevilla, Imprenta Real, Madrid, 1795, vol. Il, págs. 311-316. Sin embargo, en la misma obra, ORTIZ DE ZUÑIGA nos dice que en la campaña de Antequera murió Lope Ortiz de Estúñiga, Alcalde Mayor de Sevilla, tío del primero; en el cargo de Alcalde Mayor le sucedio otro Lope Ortiz de Estúńiga, primo del anterior, y continúa diciendo el autor que la Alcaldía Mayor era propia de los señores de Gibraleón y la servían por don Pedro de Estúñiga, que era su dueño, los caballeros citados, todos parientes suyos. Ibidem, pág. 326.

(34) Confirmación del cargo por Juan II en enero de 1444 en OSUNA, Caja Especial 215-13-3. También hay otra confirmación, anterior, del año 1422 en ibidem, Carpeta 171-17.

(35) Ibidem, Leg. 289-2. Copia del siglo XVIII. En carta del 20 de febrero de 1430, Juan II notificaba al Concejo de Ledesma la merced que habia hecho de la villa a Pedro de Estúñiga, y lo apremiaba para que lo tomasen por su señor. $/$ bidem, Leg. $2893^{-1}$.

(36) Pedro I de Estúñiga, junto a sus hermanos, se halló en la batalla de La Higuera distinguiéndose por su valor. ORTIZ DE ZUÑIGA, op. cit., págs. 380-381.

(37) Noticias acerca de sus actividades como capitán mayor de la frontera en A(rchivo) M(unicipal) de S(evilla). Actas Capitulares de los años 1437, 1438 y 1439. También en ORTIZ DE ZUÑIGA, op. cit., págs. 411-412. 
(38) OSUNA, Leg. $289-7^{-1}$.

(39) Ibidem, Leg. 298-1.

(40) Ibidem, Leg. 299-2-1-2

(41) CHACON, G., "Crónica de Don Alvaro de Luna, ed. de Juan DE MATA CARRIAZO en Colección de Crónicas de España, Madrid, 1940, págs. 324-325.

(42) QUADRADO, J. M., op. cit., pág. 267.

(43) En 1430, Juan II le hizo merced a Alvaro de Estúñiga de que a la muerte de su padre le sucediera en el cargo de Justicia mayor. OSUNA, Carpeta 40-3. Confirmación del cargo por Enrique IV en Caja Especial 215-13-3.

(44) A.M.S., Actas Capitulares 1450, fol. 150. AHN, OSUNA, Carpeta 14-3.

(45) Desde 1433 aparece Alvaro I de Estúniga junto a Pedro I de Estúñiga actuando en las sucesivas ligas nobiliarias que se forman en el reino. B.N., Mss. Res, 17, fol. 11.

(46) VALERA, Diego de, «Memorial de diversas hazañas. Crónica de Enrique IV", ed. de Juan DE MATA CARRIAZO, vol. IV de la Colección de Crónicas Españolas, Madrid, 1941, pág. 33.

(47) OSUNA, Carpeta 50-9. Confirmación de la merced en Leg. 314 (11)-20. Seguro que hicieron el marqués de Villena y el conde de Benavente a don Alvaro de Estúñiga de que continuaría en la posesión de Trujilio en Carpeta 50-10.

(48) VAL VALDIVIESO, M. I., «Resistencia al dominio señorial durante los últimos años del reinado de Enrique IV", en Hispania, 126, 1974, págs. 63-65.

(49) OSUNA, leg. 300-1.

(50) La carta de merced, en OSUNA, Leg. $279-3^{-t}$. Otorgamiento de título de duque de Arévalo en Leg. 279-4.

(51) OSUNA, Carpeta 41-6.

(52) Ibidem, Carpeta 42-1.

(53) SUAREZ FERNANDEZ, L.; CARRIAZO ARROQUIA, J. de M., “La España de los Reyes Católicos (1474-1516)", vol. I en Historia de España dirigida por Ramón Menéndez Pidal, pág. 151.

(54) Ibídem, pág. 168.

(55) Capitulaciones entre los Reyes Católicos y los duques de Arévalo en OSUNA, Leg. $279-8^{-7}$.

(56) Testimonio de este hecho en ibidem, Leg. 318 (1)-5 $5^{1-2}$.

(57) QUADRADO, op. cit., pág. 268.

(58) GUTIERAEZ CUADRADO, op. cit., pág. 21.

(59) AMB, Caja de Hierro, Fuero, fol. $7 \mathrm{v}$.

(60) OSUNA, Leg. 214-9-1,

(61) Ibidem, Leg. 216-2.

(62) Ibidem, Leg. 214-9 ${ }^{-1}$.

(63) Así lo señala el documento. Ibidem. De la misma opinión es QUADRADO, J. M., op. cit., pág. 267.

(64) GARCIA DE VALDEAVELLANO, op. cit, pág. 60.

(65) OSUNA, Leg. 214-9-1.

(66) DEL ESTAL, J. M., "Erección por Jaime II de una feria en Alicante», en Instituto de Estudios Alicantinos, N. ${ }^{\circ}$ 16, Alicante, 1979, págs. 153-174.

(67) OSUNA, Leg. 214-9-

(68) La narración está en ibídem, Leg. 216-2 precediendo al texto de las ordenanzas. A título informativo diremos que la alcabala de la feria sin el lusillo que en 1454 recibió el señor de la villa ascendió a $82.520 \mathrm{mrs}$. El lusillo y la bohoneria de la feria rentó $9.870 \mathrm{mrs}$. de alcabala. MARTINEZ MORO, J., La renta feudal en la Castilla del siglo XV: los Stúnigas, Universidad de Valladolid, Valladolid, 1977, pág. 53.

(69) GARCIA DE VALDEAVELLANO señala que ferias y mercados de Castilla solian ubicarse en las afueras de la población (caso de Avila), o en las plazas (caso de Valladolid), op. cit., pág. 173; SANCHEZ ALBORNOZ declara que el mercado se situaba en las afueras de León, Una ciudad de la España cristiana hace mil años, Rialp, Madrid, 1976, 6." ed., pág. 30 y sigs.

(70) OSUNA, Leg. 216-2.

(71) Vid. nota 68.

(72) OSUNA, Leg. 217 (II)-5-6.

(73) Sucedió en las Cortes de Toledo de 1480. En esta reunión se recordó también que Enrique IV, en las Cortes de Ocaña, revocó todos los mercados francos que tenía dados en cualquier ciudad o villa. Cortes de Castilla. Cortes de Toledo año 1480, punto 115, págs. 189-190. 
(74) Una carta dada por Isabel la Católica el 20 de octubre de 1489 recuerda que este ordenamiento ya se dio con anterioridad. OSUNA, Carpeta 42-5.

(75) Ibidem, Leg. 217 (II)-5 $5^{-6}$.

(76) Ibidem, Leg. (II) $-5^{-6}$ bis.

(77) Ibidem, Carpeta 42-5.

(78) Ibidem, leg. 216-2.

(79) En el encabezamiento del texto de las ordenanzas se indica lo señalado.

(80) En el documento que nos habla acerca de la historia de la Feria de Béjar. OSUNA, Leg. 216-2.

(81) VALDEAVELLANO, op. cit., pág. 110 y sigs.

(82) A.M.B., Caja de Hierro, Fuero, fol. $7 \mathrm{v}$.

(83) Problemas motivados por los precios de los alquileres fueron frecuentes en las ferias. Una ordenanza para la Feria de Medina del Campo de 1421 instituia el cargo de aposentador mayor, encargado de asignar alojamientos a los mercaderes y regular las diferencias que pudieran surgir entre ellos por este motivo. DUFROURCQ, Ch. GAUTIER-DALCHE, J., Historia económica y social de la España cristiana en la Edad Media, Ediciones El Albir, Barcelona, 1983, pág. 264.

(84) Vid. nota 78. 